\title{
Restarting "Normal" Life after Covid-19 and the Lockdown: Evidence from Spain, the United Kingdom, and Italy
}

\author{
Cristiano Codagnone ${ }^{1,2,3} \cdot$ Francesco Bogliacino $^{4,5}$ (D) . Camilo Gómez ${ }^{4,5}$. \\ Frans Folkvord ${ }^{2,6} \cdot$ Giovanni Liva $^{2} \cdot$ Rafael Charris $^{5,7} \cdot$ Felipe Montealegre $^{4,5}$. \\ Francisco Lupiañez Villanueva ${ }^{2,3} \cdot$ Giuseppe A. Veltri $^{8}$
}

Accepted: 20 April 2021 / Published online: 8 May 2021

(C) The Author(s), under exclusive licence to Springer Nature B.V. 2021

\begin{abstract}
In this article, we examine the expectations of the economic outlook, fear of the future, and behavioural change during the first Covid-19 wave, for three European countries (Spain, the United Kingdom, and Italy) that have been severely hit. We use a novel dataset that we collected to monitor the three countries during the crisis. As outcome variables, we used expectations (e.g., economic outlook, labour market situation, recovery), fear (e.g., scenario of new outburst, economic depression, restriction to individual rights and freedom), and behavioural change across the following dimensions: savings, cultural consumption, social capital, and risky behaviour. We provide descriptive evidence that is representative of the population of interest, and we estimate the impact of exposure to shock occurred during the crisis on the same outcome variables, using matching techniques. Our main findings are the following: we detected systematically negative expectations regarding the future and the recovery, majoritarian fears of an economic depression, a new outbreak, and a permanent restriction on freedom, a reduction in saving and in social capital. Exposure to shocks decreased expected job prospects, increased withdrawal from accumulated savings, and reduced contacts with the network relevant to job advancement, whereas it had inconclusive effects over fears.
\end{abstract}

Keywords COVID-19 $\cdot$ Fear $\cdot$ Expectation $\cdot$ Behavioural change $\cdot$ Negative economic shocks

JEL Classification D84 · D90 · D91 · I12 · H12

\section{Introduction}

The year 2020 has witnessed an unprecedented series of events that put into question the institutional structure of the world economy (the rules of the game) and the social fabric of our societies. In March 2020, Covid-19 was declared a pandemic by the World Health

Francesco Bogliacino

fbogliacino@unal.edu.co

Extended author information available on the last page of the article 
Organization (WHO, 2020). Almost everywhere, countries adopted strict mitigation strategies, inspired by China's success in the containment and suppression of the contagion. Nonetheless, the combination of the Covid-19 and the mitigation strategies has produced one of the worst crises of the last century, in terms of both economic and health consequences, and is threatening a global depression (Bibby et al., 2020; Van Bavel et al., 2020). Uncertain prognoses for when the lockdown will be reduced and people can restart their lives again, economic expectations, looming severe shortages of resources for testing and treatment, public health measures that infringe on personal freedoms, large and sometimes even growing financial losses, and conflicting messages from authorities, are considered to be the major stressors that undoubtedly will contribute to widespread emotional distress and increased risk for sever health problems, associated with the COVID-19 crisis (Duan and Zhu, 2020; Pfefferbaum \& North, 2020).

Pandemic outbreak and mitigation strategies produced tangible shocks (e.g., losing one's job, loss of earnings, having to do home schooling, impossibility to keep social contacts) compounded by a climate of radical uncertainty on the epidemiological and clinical aspects of the pandemic, on when and how social distancing would be lifted, and on the economic consequences. Different personalities have argued in favour of the necessity to restart, i.e. for the societies to converge to a new normal, where collective actions, markets, and institutional mechanisms can coordinate individual plans.

We claim that to envision the post pandemic restart of our societies, an important role is played by expectations, emotions (e.g., fear, stress, anxiety), and behavioural change in key dimensions (e.g., saving, cultural consumption, networking, health). First, expectations are a fundamental coordination mechanism for our economies. A significant change in the expectations about the future, being those rational or mainly based on emotions, can have a substantial macroeconomic impact. For instance, pessimistic expectations about the labour market situation may have significant negative effects on aggregate consumption and wage growth, because consumers and employees restrain themselves in their consumptions when they are uncertain about the future (Garz, 2013). Similarly, higher uncertainty about the future economic situation causes firms to temporarily pause their investments and hiring (Bloom, 2009). Second, our societies are also hardwired to defuse fears and other negative emotions. Fear is an ill advisor at individual level, because it impairs the normal functioning of the cognitive control and other processes that occur in the pre-frontal cortex (Roth et al., 1988; Öhman, 2007; Eysenck, 2013). At the aggregate level, fear is a threat to our political systems, whose rules are based on the capacity of collective bodies to aggregate preferences and of rational dialogue to settle conflicts and disputes (Nussbaum, 2004; Bobbio, 1980; Sartori, 1987), whereas fear can be exploited by populist forces, as it has been occurring in the last decade. Third, although a looser concept, behavioural change captures the basic tenet that certain decisions have long run consequences, if they are related with savings, patterns of consumption, health behaviour and networking. Bad health habits hamper future productivity (Lenhart, 2019), deaccumulation of savings leaves a person exposed to future shocks, as typical of poor households (Banerjee and Duflo 2007), giving up connections decreases the chances to take advantage of future job or carrier opportunities (Sibley et al., 2020), changing cultural consumption patterns during the pandemic may have several adverse effects, for it plays a key role as generative mediator of social identities and stratification (Katz-Gerro, 2004), increasing already existing inequalities in cultural capital (Bennet and Silva, 2006).

In this study, our first aim is to understand and visualize under what circumstances the new normal will take place. To accomplish it, we provide a descriptive account of expectations, fear, and behavioural change in three countries, using a representative sample, 
measured at the lifting of the lockdown, just after the worst of the first wave is over. Our second aim is gaining insights into how the crisis has disrupted expectations, emotions, and behavioural change. Therefore, we need to identify how the degree of exposure to shocks, occurred during the crisis, affected those variables. This can shed light on how to target policies to soften the impact of the crisis and to better shape the long run recovery. These objectives can be stated through the following research questions: What are the expectations and fear towards the future and the behavioural change occurred during the first wave of the pandemic in a representative sample of the population of Italy, Spain and the United Kingdom? What are the differences in those outcomes attributable to the degree of exposure to labour market and health shocks?

Addressing these two aims contributes to increase our understanding of some of the psychological, social, and economic consequences of the current economic halt. There is an emerging body of literature that is starting to look at the unequal impact of lockdown on different social groups and at the potential for structural increase in inequalities (AdamsPrassl et al., 2020a, 2020b; Bergamini, 2020; Brunori et al., 2020; Hanspal et al., 2020; Perugini \& Vladisavljevic, 2020; Tabner, 2020). Evidence on how the gradient of exposure has shaped expectations and emotions about the future, and behavioural change is still largely missing.

To fill the gap in the literature and to provide some important insights for policy makers, we will use a subset of the data from a longitudinal study conducted in three waves in the UK, Spain and Italy between April 24 and May 20 (Bogliacino et al., 2020). We will focus on data from wave three, where we elicited expectations (general, labour market situation, recovery), fear (scenario of new outburst, economic depression, restriction to individual rights and freedom), and behavioural change across the following dimensions: savings, cultural consumption, social capital, ${ }^{1}$ risky health behaviour. One important added value of these data, which is missing in other sources, is that we collected these outcome variables between the 10th and the 20th of May, when the three countries were slowly exiting the lockdown, and this represents the perfect timing to both detect behavioural change during the worst phase of the crisis, and to elicit expectations and fear towards the future while the reopening is under way. Additionally, we will use the information from the three waves to identify the degree of exposure to shocks, by measuring the negative events that respondents experienced during the Covid-19 and lockdown crisis. Our results have robust external validity, because we started with a representative sample (in wave I) and we plausibly correct for selection bias (technically, we use machine learning techniques to estimate the probability of dropout, conditional on baseline characteristics, and then reweight the data). A methodological choice of the paper concerns the application of matching technique to ensure that the outcomes of those highly exposed are compared with the outcomes of less exposed who share their characteristics. This strategy allows us to compute a counterfactual, establishing the difference in expectations, fears, and behavioural change had the persons never suffered an increase in the degree of exposure. To do so, we first present a synthesis of the causal paths (Direct Acyclical Graphs, DAG, Cunningham, 2018; Pearle,

\footnotetext{
1 Social capital is defined in slightly different ways depending on the theoretical perspective (Bourdieu, 1986; Coleman, 1988; Putnam 1993, 2000; Putnam 1993, 2000). At a very basic level it can be said that the concept entails both normative (norms and values) and instrumental dimensions (networks). At macro level social capital can be equated to civic sense entailing norms, social values, trust, and social network (especially participation in association). It is a source of an important systemic resource such as generalised trust. At a more micro level social capital can be defined as the ensemble of social networks that can enable individuals to gain access to desired resources and outcomes.
} 
2009) that go from (crisis driven) shocks to the outcome variables, to make sure that we balance subjects on observables characteristics, and we reasonably estimate a difference in outcome with respect to a counterfactual. Although unobservable characteristics may vary along the degree of exposure, a strength of our data is that we can focus on the intensive margin, which is less subject to the risk of endogenous selection, instead of the extensive margin (comparing exposed with unexposed), where the consequences of self-selection appear to be more serious. Since our identification relies on our DAG, the causal claims are conditional on the plausibility of our model.

According to our estimates, in the three countries we detected shared pessimism and expectations of recovery that goes well beyond the current year; widespread fears, especially with regards to an economic depression, and, finally, disruption of social capital, deaccumulation of savings, and unhealthy behaviour, with potential long run consequences. There is a gradient according to the degree of exposure, at least in terms of use of savings, social capital, and expectations regarding labour prospect. The effect on fears is not robust to different estimators, but it appears to be consistent also with the hypothesis that the severity of shocks induced a reassessment of the future.

In Sect. 2, we describe how the uncertainty of the current crisis shaped outcome variables and present a scheme of the causal paths linking shocks to expectations, fear, and behavioural changes. In Sect. 3, we illustrate our data and methodology, and in Sect. 4 we comment the results. In Sect. 5 we discuss the implications of our findings and we conclude. The questionnaire and the supplementary statistical analyses are in the Supplementary Online Materials (SOM).

\section{Covid-19 and the Future: Theoretical Framework}

In this section we present the theoretical underpinnings of our analysis and methodology.

\subsection{Reshaping of Expectations, Fears, and Behavioural Change Under Radical Uncertainty}

In decision theory, choices shape the collective outcomes for a given institutional setting (Gintis, 2007). These choices are determined by beliefs, preferences, and constraints: beliefs give coordinates while facing uncertainty, preferences rank alternatives in each choice set, and constraints determine those choice sets.

Beliefs, preferences, and constraints change in response to the environment. Beliefs are constantly updated in response to new data, sometimes this updating is biased because of phenomena such as motivated reasoning and confirmatory bias (MacFayden, 2006). Although theories of rational behaviour assume preferences to be stable, in reality "preferences are ineluctably a function of such parameters as hunger, fear, and recent social experience, and beliefs can change dramatically in response to immediate sensory experience" (Gintis, 2007: p. 4). Finally, past decisions affect available choices: mistakes can have long run consequences, such as in poverty traps (Barret et al., 2019), or as we said in the introduction, because bad health habits or losing connections may have long run consequences in terms of both health and economic opportunities (Machin \& Manning, 1998; Bonanno et al., 2010).

We conjecture that in this contingency, beliefs, fear, and rules of behaviour changed because the crisis has introduced large doses of uncertainty, and because the policy 
response may have further fuelled this uncertainty. Governments, in fact, generally abstained from providing contingent scenarios for the mid-term, while the main decisions appear to have been guided by the precautionary principle instead of the cost benefit analysis (Codagnone et al., 2020), and the former is prone to trigger availability cascades (Sunstein, 2018).

The uncertainty and ambiguity surrounding the pandemic itself and lockdown have both objective and subjective dimensions, both of which have been framed ${ }^{2}$ in the public discourse that accompanied lockdown. The way governments initially framed the pandemic and the way to contain it has been picked up and exacerbated in the media. It can be argued that using the metaphor of the war was unfortunate to maintain uncertainty and ambiguity under control: war is associated with danger, and war is a state of emergency where the person in charge is taking the decisions without leaving discretionary margins to those low in the hierarchy, but in this case, things were made worse by the lack of any clear strategy for the near future and the return to normality. Additionally, communication by the governments fuelled uncertainty because of the lack of robust evidence to support many aspects of this pandemic, that were afterwards rectified, e.g. the lethality of the virus, the numbers of contagion, the infectiousness, the availability of tests, the capacity of healthcare systems to cope with the wave of patients in need of intensive care, the research for a vaccine. Second, uncertainties surround also the negative economic short and long run consequences of lockdown (Baker et al., 2020): the economic impact of the pandemic, the policy responses, the speed of the recovery, the survival of firms, consumers' spending. If we consider all these aspects of uncertainty and ambiguity, there are strong reasons to believe that they induced a reassessment of the expectations about the future. Scholars in China have already tested the relationship between the ambiguity shock induced by Covid19 and the macroeconomic expectations ( $\mathrm{Li}, 2020)$. These emergent findings and stylized facts confirm that the provision and the framing of information by institutional channels and by the media are having an impact on people's economic sentiment, in line with previous results in other contexts (Garz, 2013; Goidel et al. 2010).

In addition, lockdown introduced some mandatory restrictions that forced immediate behavioural change, for individuals were asked to stay home and many economic activities were temporarily closed (Baker et al., 2020). Spending levels dropped because of the reduction of public contact, social activities, the closure of sport and shops and the suspension of a large number of economic activities. At any rate, this temporary behavioural change may become permanent when it is crystallized by the occurrence of full-blown shocks.

We expect citizens in Spain, the United Kingdom and Italy to hold a majoritarian negative attitude towards the future, both in terms of personal and general state of the economy (Hypothesis 1), and in terms of fear of dystopic scenarios (H2, new pandemic outburst, economic depression, restriction on freedom and rights). Additionally, we expect a self-reported increase in risky behaviour (H3), an increased use of saving (H4), and a decrease in social (relational) capital (H5). We lack a clear prediction in terms of cultural

\footnotetext{
${ }^{2}$ In this respect a brief detour on the framing literature helps sharpen some aspects relevant to our paper. The framing perspective, originating in other disciplinary fields (Tversky and Kahneman 1981; Benford \& Snow 2000; Klandermans 1997; Snow and Benford 1988; Snow, Rochford, Worden, and Benford, 1986; Entman 1991, 1993; Kuypers 2010), in the last two decades has been increasingly applied to the study of politics and policy making and related communication strategies (Béland et al., 2016; Carstensen and Schmidt, 2016; Seabrooke and Wigan, 2016; Mügge, 2016; Jones, Thomas and Wolfe 2014; Maor 2014, 2016).
} 
consumption, since the crisis has generated both a demand effect and a supply effect (a well-documented lowering down of the cost of access to cultural consumption), thus we test the hypothesis that there was no change in cultural consumption (H6).

\subsection{Shocks and Outcomes}

Besides a general effect of uncertainty on our outcome variables, there is a clear gradient in that some sectors of the population have suffered several negative events that directly affected their behaviour, the beliefs and the emotions. These are the shocks caused by the crisis. Strictly defined, negative shocks are losses of income or accumulated assets and can be classified according to the source of the loss; namely, health, labour market, natural disaster, and poverty, amongst others. We have measured in our data many of these different shocks, such as: loss of employment (job or livelihood), decrease in earning or income, temporary or definitive closing of one's business, inability to get access to sufficient food, and consequently need to apply for unemployment subsidy or for requesting the support for charities or NGOs, inability to access healthcare when needed, having sought to get tested for Covid-19, and having to home-school child(ren).

The literature shows that large variations of income for sugar cane farmers induce a cognitive toll (Mani et al., 2014). Laboratory experiments where shocks are induced as losses on accumulated earnings from a Real Effort Task confirm this evidence (Bogliacino and Montealegre 2020). It has been argued that this cognitive toll makes people concentrate on the worries, distracting attention from the ongoing decisions, which may induce counterproductive behaviour, such as lack of adherence to medication, unsafe sex, inability to comply with saving plans, procrastination etc. Asset losses can also dampen the beliefs about what it is achievable in the future (Ibáñez \& Moya, 2010; Moya \& Carter, 2019). Therefore, we expect that through these alternative channels, negative shocks affect behaviour, inducing counterproductive choices in health $(\mathrm{H} 7)$ (e.g. risky behaviour such as lack of adherence to medication, unprotected sex), in the use of savings (H8) (increasing deaccumulation), and neglect of important relationships (H9) (depreciation of social capital).

We learned from the literature on violence that mental health pathologies such as depression, chronic anxiety, and post-traumatic stress disorder, induced by victimization, may cause a state of despair, negative perceptions regarding the future, and hopelessness (Abramson et al., 1989; Moya \& Carter, 2019; Sympson, 2000; Yehuda, 2002). We also know that negative shocks during the lockdown are associated with stress, depression, and anxiety (Codagnone et al., 2020). As a result, we conjecture that shocks induce more pessimism towards the future (H10), in terms of individual labour prospect and lower demand for cultural consumption (H11), because hopelessness is associated with a sense of alienation. We speculate that a similar effect extends to the general fears of the future and aggregate economic prospect (H12).

\subsection{Causal Mechanisms: Direct Acyclical Graph}

To estimate the impact of shocks on outcomes, in absence of exogenous variation that would balance other plausible causal mechanisms, we need to put forward the causal paths that connect, directly and indirectly, shocks to expectations, fear, and behavioural change. While the direct path is the causal impact of interest (ceteris paribus, what is the effect of shocks), the backdoor paths are confounding factors, because they induce spurious correlation by influencing why certain individuals may be more prone to severe shocks and 


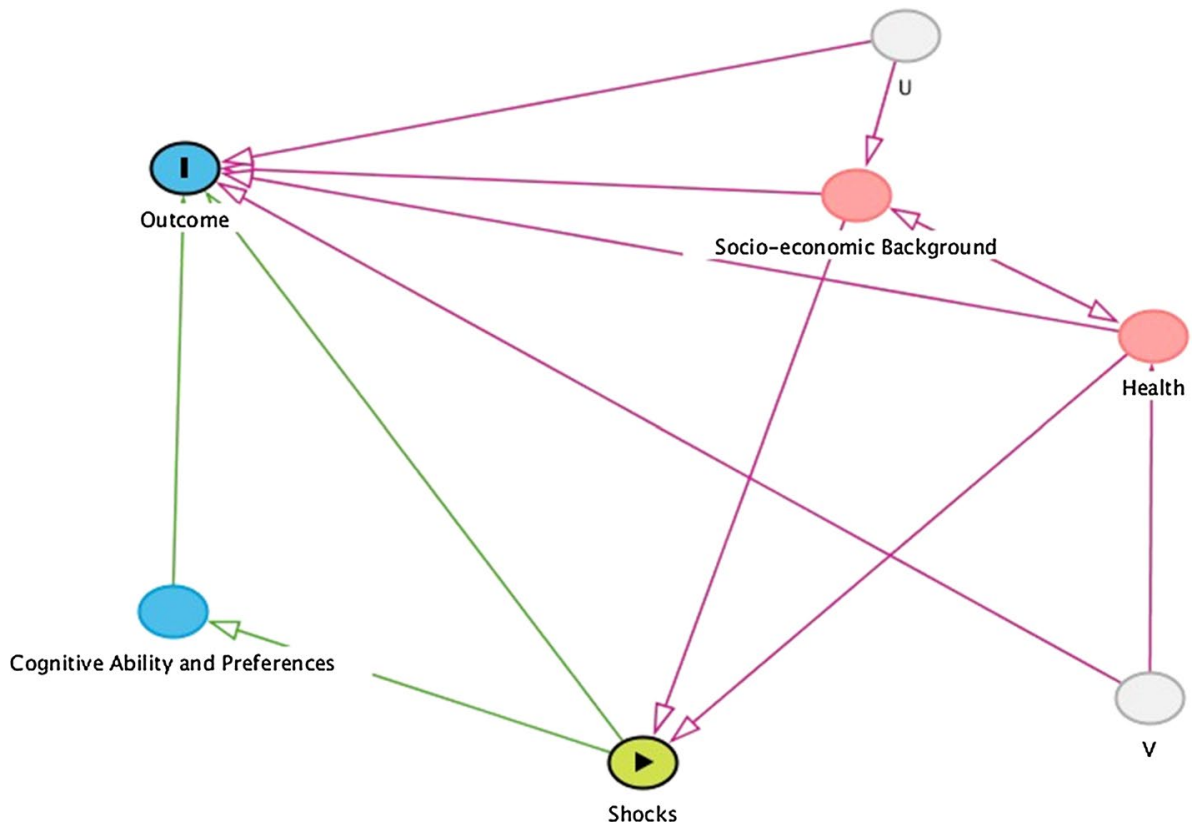

Fig. 1 The DAG of shocks and beliefs, fears, and behavioural change

have systematic differences in terms of outcome variables. Due to these underlying differences, we would have observed different expectations, fear and behaviour, had these individuals not being exposed to severe shocks. Once we close these backdoor paths, properly controlling for variables measuring these connections, we can then compute meaningful comparisons. ${ }^{3}$

A Directed Acyclic Graph (DAG) of the problem is plotted in Fig. 1 using dagitty (Textor et al., 2016). A DAG uses the language of Graph theory to show the causal connections between the relevant variables (Pearl, 2009). In the DAG, outcomes represent the dependent variables of interest. The exposure variable is the shock. We are interested in the direct connection between shocks and outcome. Nevertheless, there are backdoor paths that connect shocks and outcome. Two of them are through confounds: these are omitted variables that explain both exposure to shocks and outcome. One is through a mediator mechanism: the fact that shocks affect preferences and cognitive performance. Since Bogliacino et al., (2021) estimated the relationship between shocks and preferences, we focused here only on the direct path between shocks and outcome (and not on the indirect path mediated by

\footnotetext{
3 To understand the logic of this identification strategy, let us use a textbook example (Cunningham, 2018). Assume that we want to test if being in first class of Titanic increases the probability of survival. It is argued that the social norms in the sea recommend women and children first, thus if the latter categories where more represented in first class, simply estimating the probability of survival by class of the boat may confound the causal effect of social norms. To overcome this inferential problem, we need to compare between classes of the boat, within gender and age cells. In the same vein, in our setting, we should postulate causal mechanisms that may confound the relationship between shocks and beliefs, fears, and behaviour and define proper control variables to exclude these confounding factors.
} 
preferences). In the graph, there are also unobservables, $\mathrm{U}$ and $\mathrm{V}$, which we assume are affecting confounds. We will justify this assumption below.

One first block of relevant confounds is represented by socio-economic conditions. ${ }^{4}$ We know from the literature on poverty that poor households are more frequently hit by negative shocks (Haushorfer and Fehr 2014). We also know that low socio-economic background predicts exposure to negative health shocks in the context of the current crisis (Codagnone et al., 2020). Differences in socio-economic background are obviously related with differences in expectations, fears, and behaviour. Well established research argues that socio-economic background influences how beliefs are updated and used facing uncertainties and, especially, to shape the subjective interiorization of constraints that in turn determine the subjectively perceived choice set and eventually behaviour. This hypothesis is amply confirmed in the literature on the psychology of class (Manstead, 2018), in classical sociological works (e.g. Bourdieu, 1977, 1986) and also in recent well-known books monographs on inequality (Atkinson, 2015; Wilkinson and Pickett 2017). Current class position affects the way people think, their beliefs and, consequently, their behaviour (Doney et al., 1999), for instance: moving down the social hierarchy from middle to lower positions, individuals are more likely to see social events in situational terms for they have a lower sense of personal control (Manstead, 2018). According to Bourdieu's theory, class position and the volume and structure of capital that agents possess shape their habitus of individuals, which is defined as a system of dispositions, appreciations, and practical mastery (Bourdieu, 1977, 1980, 1984, 1986). The habitus is a generative mechanism at work in a wide variety of different contexts and, thus, influences a large variety of behaviors. Thus, one would expect that there is clear social gradient in the way different individuals are experiencing the uncertainty and shocks produced by Covid-19 and related mitigation strategy: more vulnerable groups feel less control and tend to have more negative expectations, to be more fearful, and to have already changed their behaviour in defensive and/or disfunctional manner. ${ }^{5}$

A second block of confounds is associated with the health condition, and in this particular context with susceptibility and vulnerability from the Covid-19. In biology, susceptibility is the extent to which a person would suffer, once contracted the virus. Vulnerability is the likelihood to contract it and depends on the degree of communitarian exposure. In addition, there is an ample literature showing that health status and particularly having chronic conditions compound the effects of negative shocks. Chronic conditions, in the same way as unexpected health shocks, besides producing tangible direct (medical costs) and indirect effects (workday loss, loss of productivity, human capital deterioration, decrease in savings and consumptions), have also intangible psychological effects such as anxiety, fear, and suffering (Mendola et al., 2007; Wagstaff 2007; Jones et al., 2020).

A third block of variables concerns preferences traits. Preference traits are usually made of two components: the first one is relatively stable, and explain consistency of choice in many domains, the second one is deemed to be affected by life experience (Gintis, 2007). We know

\footnotetext{
${ }^{4}$ By definition of "Acyclical" graphs, the arrow cannot be bidirectional, i.e. socio-economic status and shocks cannot directly influence each other. This implies that this view of causality is ill equipped to deal with simultaneity. Notice however that if the arrow would go in the opposite direction, this would not harm identification as we are controlling for SES. A similar argument would hold for health below.

5 Notice that some authors argue for non-linearity, as middle class may suffer from uncertainty during crises more than lower classes since they have more to lose and higher social expectations (Kiess and Lahusen, 2018; Steijn et al., 1998), and more than upper classes as the latter are simply less exposed.
} 


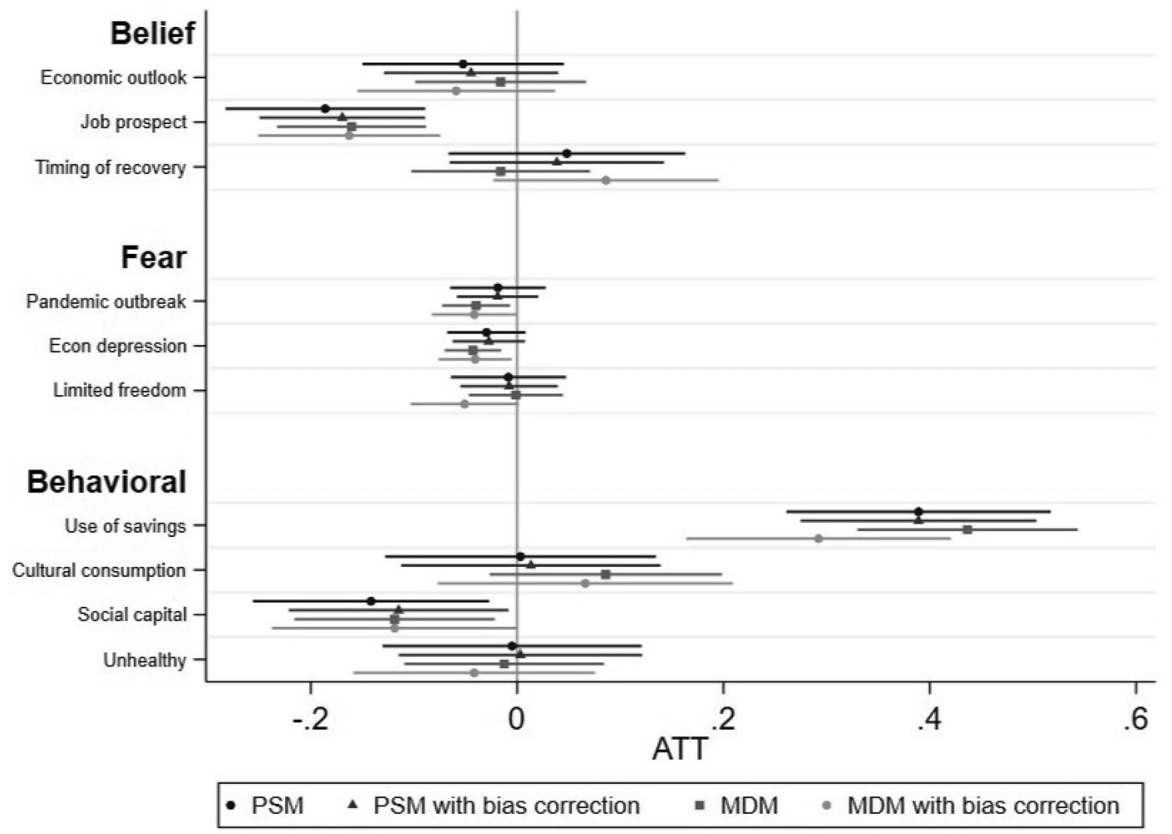

Fig. 2 Average treatment effect on the treated (ATT) by methods

from multiple quasi experimental and experimental studies that negative shocks, alone or in conjoint with other phenomena (e.g. trauma) affect preferences in different domain: increasing time discount (Haushofer et al., 2014; Voors, 2012), risk aversion (Decker and Schmitz, 2016), reciprocity (Cavatorta et al., 2020), trust (Cassar et al., 2017), and cooperation and prosociality in general (Bauer et al., 2016). At the same time, preferences are obviously related with beliefs and choice (on self-serving beliefs, Mobius et al., 2011; Eli and Rao, 2010; Grossman and Owens, 2012, and on preferences explaining choices, Varian, 1982; Andreoni \& Miller, 2002). As a result, preference and cognitive function operate as a mediator or mechanism.

One could argue that there are other unobservable variables that explain beliefs, fear, and behavioural change. In Fig. 1 above, we labelled them $U$ and V. These other varying factors do not harm our identification of the causal effect, as long as they are mediated by health and socio-economic factors. Given our review of the literature, we claim that this identifying assumption is reasonable, but results should obviously be interpreted conditionally on its plausibility.

Based on this review of the literature, in the estimation of counterfactuals fears, beliefs and behaviour in absence of strong shocks, we need to control for baseline socio-demographic characteristics to close the path of the social gradient on the outcome variables, for preference traits to close the path shocks-preferences-outcome, and for baseline health status to close the one involving health, shocks and outcomes. (Fig. 2) 


\section{Methodology}

\subsection{Data}

The policy context of the three countries is reported in the SOM, Sect. 2, Country Cases. The data used in this paper comes from the large-scale data collection project by Bogliacino et al. (2020). In this project, a random sample drawn from a representative online panel in Spain, United Kingdom and Italy was interviewed three times, first in the week from the 24th of April to the 1st of May $(\mathrm{N}=10,551)$, then in the week from the 2nd of May to the 9th of May $(\mathrm{N}=4490)$, and finally from the 10th of May until the 20th of May $(\mathrm{N}=3191)$ (hereafter, wave I, wave II, and wave III). We restricted participation to 18-75 years old, no other data selection was performed on those who completed the interview. The project included longitudinal measures and specific experimental manipulations in each wave. All the materials and methods are reported in the pre-registered study. ${ }^{6}$ Ethics approval was obtained from the Institutional Review Board of the Universitat Oberta de Catalunya. All respondents provided written informed consent. The relevant portions of the questionnaires are reported in Supplementary Online Material, Sect. 1.

Outcome variables for this paper have been collected in wave III, through three blocks of questions (see questionnaire wave III, Q8-Q15). The first block included expectations and it is made of three questions, two on optimism over the economic outlook and personal job outlook (taken from Eurobarometer) and one on the length of the recovery (standard formulation). The second block included questions on evaluating how likely a certain future scenario is considered (standard formulation) and the scenarios evaluated were: (1) A new outbreak of the disease; (2) An economic depression; and (3) A permanent restriction to our rights and freedom. Participants are asked to answer on a Likert scale from one to four. The third block of questions asked about behavioral change in the lockdown with respect to normal. Since we had to design this last set of questions, we validated them with professional psychometric standards. The questions asked were about use of savings, cultural consumptions, maintenance of relevant personal contact (social capital), and unhealthy lifestyle.

From wave I, we matched all the baseline information on socio-demographic characteristics and health status. From wave II, we collected information on preferences (Falk et al., 2018 Global Preference Survey) and cognitive function (Cognitive Reflection Test, Frederick, 2005). These enabled us to close the backdoor paths as discussed in the previous section.

To estimate the size of exposure to negative events during the period of data collection, we use the following question "Over the past week, have any of the following events happened to you?" (stressful events shocks, hereafter) and includes having been forced to stay at home, having lost the employment, having suffered a reduction in earnings, having had to homeschool children, having been unable to access healthcare, having been unable to get access to food, sought to get tested for Covid-19, having had to apply for unemployment subsidy or government support, and sought help from charities. Answer per each item is Yes/No.

\footnotetext{
6 The software used for the analysis was Stata 15 (StataCorp 2017). We also used the kmatch routine (Zou and Schonlau, 2021) and rforest routine (Zou and Schonlau, 2021).
} 


\subsection{Controlling for Selection Bias}

While the original sample was representative, the sample of wave III is affected by attrition. To make sure that the outcome variables reflect the population of interest, we define importance weights equal to the inverse of the probability of survival (defined as not dropping out) until wave III. The true likelihood of survival in the population is not observable, thus we estimate the conditional probability, using a set of 60 variables from the answers in questionnaire in wave I. These variables cover participants' sociodemographic characteristics, health condition, and geographical location to have a well-defined outlook of attributes that could predict the dropout. The complete list of variables is presented in SOM Table S1.

While we could estimate a standard linear probability or logit model, since we are focusing on prediction, we opted for a machine learning algorithm, which is more accurate in predicting attrition. The estimation method follows a random forest algorithm. This algorithm is characterized by using numerous decision trees. The central idea is to create an uncorrelated forest of decision trees to make the prediction. To build each uncorrelated decision tree, the method uses two strategies: random selection of features and bagging. The random selection of features is the selection of a random subset of features (e.g. age, gender, geographical zone, etc.) from all the variables selected for the prediction to create the decision nodes in each tree. This implies that amongst the trees in the forest, we have considerable diversification in terms of decision nodes. Bagging or bootstrap aggregation consists of randomly select with replacement a training sample of size $\mathrm{N}$ from the database to run the estimation in each tree. Observations not included in the training sample are defined as the out-of-bag sample. By using bagging, it is possible to calculate the out-of-bag error (OOB-error). The OOB-error is a measure of how good the prediction of the random forest is when it is used in the out-of-bag sample. The OOB-error provides an overview of the quality of the random forest. If the convergence of the OOB-error is reached rapidly with respect to the number of trees, the algorithm is suitable for the prediction. We set the random forest algorithm with 550 trees (iterations), a training sample of size $N=10,551$, and with 60 features to be randomly selected for each tree. By using all the data, we somehow overfit and maximize the accuracy, however, we show in the SOM that results are consistent when we use subsamples of the data.

\subsection{Identification Strategy}

To identify the causal effect of exposure to Covid-19 and lockdown crisis, we use a selection on observable research design and we estimate via matching. Hereafter, we define treated individuals those highly affected by the crisis, and control individuals those who were not. We focus on intensive margin to soften the threat of endogeneity (i.e. we compare a difference of degree instead of a switch from non being expose to being expose). Matching means reconstructing ex post a control group using a metric defined over observables to identify the closest non treated individuals to each treated unit. Stated in simple words: we would like to estimate a counterfactual, what would have happened if those severely affected by shocks had not been hit, and we would need a sample of non-severely hit citizens that, on all the relevant explanatory factors of the outcomes, are on average non different from those severely hit. We reconstruct such a sample, ex post, searching 
for individuals which are close enough according to the observable characteristics, whose explanatory power of the outcomes is significant.

To measure treatment status, we create an index of stressful events shocks. As we said in the data section, we used the question "Over the past week, have any of the following events happened to you?". Since responses are Yes/No to each potential source of shocks, we can sum over the total number of shocks. We classify participants either as treated or control, using the median of the index as threshold. Participants above the median value were assigned to the treated group and participants below the median to the control group.

The assignment to the two groups is not random; as a result, simple mean comparison between treated and untreated group is affected by selection bias. To control for this selection bias, we match participants from treatment and control group using two measures of distance in terms of observables: the likelihood of getting the treatment, conditional on the observables (Propensity Score Matching, PSM), and a measure of distance defined over the space of observables (Mahalanobis Distance Matching, MDM).

The identification assumptions are the conditional independence assumption (CIA) and the common support. The former states that once we close the backdoor paths, i.e. we control for the variables that may confound shocks and outcomes, the assignment to shocks is as good as random. In simple words, this implies being able to measure through observables all relevant omitted variables. To satisfy this central assumption, we carry out a rigorous selection based on a theoretical criterion to identify which observable variables affecting the outcomes could be driving as well the likelihood of being hit by shocks. This assumption is untestable, but our theoretical background is transparently reported in Sect. 2. The second assumption is the common support: this means that in the domain defined by the control variables, the likelihood of being affected by shock is strictly positive. This corresponds to avoiding comparing individuals hit by shock with individual different, in that they have a zero likelihood of being severely affected. This second assumption can and will be tested empirically.

The coefficient we estimate is the effect of the intensity of the shock on beliefs, fears, and behavioral changes over those that were severely hit (average treatment effect on the treated, ATT hereafter). To state it simply, it is the difference between the outcomes observed after having been severely hit by shocks and the outcomes that we would have observed on the very same individuals, if they had suffered only mild shocks.

As we said, we use two methods. In the first method, we follow the standard propensity score matching method proposed by Rubin (1977), and Rosenbaum and Rubin (1983). First, we estimate the propensity score for each participant using a logistic regression with the set of covariates previously selected. Second, we make a nearest-neighbor matching using the propensity score estimated. In the matching, we use the three nearest neighbors with replacement (i.e. we will have three controls per each treated unit, and we can use control units more than once) and we only considered the observations that were in the common support. The second method we implement is Mahalanobis distance matching. This method matches the closest observations using a normalized and scale-invariant distance measure over the covariates. Supported by the theoretical selection and to have comparable results between methods, we use the same set of covariates used in the propensity score matching method. As before, we use three nearest neighbors with replacement and we only consider the common support. In addition, in both methods we estimate also the impact using a bias correction to adjust for differences in the covariates: this is equivalent to adjust the counterfactual for the fact that we are comparing individuals in the two groups which are not exactly the same in terms of observables and compute the causal effect with respect to this "corrected" control group. 
Table 1 What are your expectations for the year to come: will 2021 be better, worse or the same, when it comes to the economic situation (in our country)? [Corrected by dropout effects]

Table 2 What are your expectations for the year to come: will 2021 be better, worse or the same, when it comes to your personal job situation? [Corrected by dropout effects]

\begin{tabular}{lrrrr}
\hline $\begin{array}{l}\text { Belief: Economic } \\
\text { outlook }\end{array}$ & SP & UK & IT & Overall \\
\hline Better & $16.7 \%$ & $17.8 \%$ & $23.1 \%$ & $19.2 \%$ \\
Worse & $62.6 \%$ & $58.9 \%$ & $45.9 \%$ & $55.9 \%$ \\
The same & $14.8 \%$ & $13.5 \%$ & $17.3 \%$ & $15.2 \%$ \\
Don't know & $5.9 \%$ & $9.8 \%$ & $13.7 \%$ & $9.8 \%$ \\
Total & $100.0 \%$ & $100.0 \%$ & $100.0 \%$ & $100.0 \%$ \\
\hline
\end{tabular}

\begin{tabular}{lrrrr}
\hline Belief: Job prospect & \multicolumn{1}{l}{ SP } & \multicolumn{1}{l}{ UK } & \multicolumn{1}{l}{ IT } & Overall \\
\hline Better & $18.0 \%$ & $9.9 \%$ & $22.3 \%$ & $16.6 \%$ \\
Worse & $34.8 \%$ & $20.4 \%$ & $26.8 \%$ & $27.2 \%$ \\
The same & $37.8 \%$ & $55.2 \%$ & $35.0 \%$ & $43.0 \%$ \\
Don't know & $9.5 \%$ & $14.4 \%$ & $15.9 \%$ & $13.3 \%$ \\
Total & $100.0 \%$ & $100.0 \%$ & $100.0 \%$ & $100.0 \%$ \\
\hline
\end{tabular}

Table 3 What are your expectations on the recovery from the current pandemic: when do you think we will go back to our normal lives like before the outbreak? [Corrected by dropout effects]

Table 4 Among the following negative scenarios for the future, please indicate how likely you consider them? A new outbreak of the disease [Corrected by dropout effects]

\begin{tabular}{lrrrr}
\hline Belief: Timing of recovery & \multicolumn{1}{l}{ SP } & \multicolumn{1}{l}{ UK } & \multicolumn{1}{l}{ IT } & Overall \\
\hline 2-3 months & $7.0 \%$ & $5.1 \%$ & $9.6 \%$ & $7.2 \%$ \\
4-5 months & $16.5 \%$ & $13.3 \%$ & $18.1 \%$ & $15.9 \%$ \\
6 months-1 year & $36.1 \%$ & $41.1 \%$ & $40.3 \%$ & $39.2 \%$ \\
More than one year & $40.5 \%$ & $40.5 \%$ & $32.0 \%$ & $37.7 \%$ \\
Total & $100.0 \%$ & $100.0 \%$ & $100.0 \%$ & $100.0 \%$ \\
\hline
\end{tabular}

\begin{tabular}{lrrrr}
\hline Fear: pandemic outbreak & \multicolumn{1}{l}{ SP } & \multicolumn{1}{l}{ UK } & \multicolumn{1}{l}{ IT } & Overall \\
\hline Very Unlikely & $3.2 \%$ & $3.4 \%$ & $5.5 \%$ & $4.0 \%$ \\
Somewhat Unlikely & $5.9 \%$ & $12.3 \%$ & $18.4 \%$ & $12.2 \%$ \\
Somewhat Likely & $50.1 \%$ & $56.1 \%$ & $60.9 \%$ & $55.7 \%$ \\
Very Likely & $40.8 \%$ & $28.3 \%$ & $15.2 \%$ & $28.0 \%$ \\
Total & $100.0 \%$ & $100.0 \%$ & $100.0 \%$ & $100.0 \%$ \\
\hline
\end{tabular}

\section{Results}

\subsection{Expectations, Fear, and Behavioural Change in the Population, Controlling for attrition}

In Tables 1, 2, 3, 4,5, 6, 7, 8, 9 and 10 we report the descriptive statistics for the outcome variables, projected to the overall population, after correcting for selection bias. The original data, without correction, are included in the SOM, Table S3-S12. We also provide two Tables, one with the population proportions according to age, gender, and geographic 
Table 5 Among the following negative scenarios for the future, please indicate how likely you consider them? An economic depression [Corrected by dropout effects]

\begin{tabular}{lrrrr}
\hline Fear: Econ depression & \multicolumn{1}{l}{ SP } & \multicolumn{1}{l}{ UK } & \multicolumn{1}{l}{ IT } & Overall \\
\hline Very Unlikely & $2.5 \%$ & $3.5 \%$ & $3.6 \%$ & $3.2 \%$ \\
Somewhat Unlikely & $5.2 \%$ & $6.2 \%$ & $5.9 \%$ & $5.8 \%$ \\
Somewhat Likely & $28.8 \%$ & $38.3 \%$ & $41.3 \%$ & $36.2 \%$ \\
Very Likely & $63.6 \%$ & $52.0 \%$ & $49.2 \%$ & $54.8 \%$ \\
Total & $100.0 \%$ & $100.0 \%$ & $100.0 \%$ & $100.0 \%$ \\
\hline
\end{tabular}

\begin{tabular}{lrrrr}
\hline Fear: Limited freedom & SP & UK & \multicolumn{1}{l}{ IT } & Overall \\
\hline Very Unlikely & $10.7 \%$ & $13.1 \%$ & $14.0 \%$ & $12.6 \%$ \\
Somewhat Unlikely & $24.0 \%$ & $37.4 \%$ & $31.7 \%$ & $31.2 \%$ \\
Somewhat Likely & $48.0 \%$ & $38.7 \%$ & $42.7 \%$ & $43.0 \%$ \\
Very Likely & $17.3 \%$ & $10.7 \%$ & $11.6 \%$ & $13.2 \%$ \\
Total & $100.0 \%$ & $100.0 \%$ & $100.0 \%$ & $100.0 \%$ \\
\hline
\end{tabular}

Table 6 Among the following negative scenarios for the future, please indicate how likely you consider them? A permanent restriction to our rights and freedom [Corrected by dropout effects]

Table 7 If you compare your behaviour during the last four weeks with that of the four weeks of February of this year, do you think that during the last four weeks you have withdrawn from your savings [Corrected by dropout effects]

\begin{tabular}{lrrrr}
\hline Behavioural: Use of savings & SP & UK & IT & Overall \\
\hline Definitely more money in the past month than February & $17.0 \%$ & $10.1 \%$ & $19.2 \%$ & $15.3 \%$ \\
Probably more money in the past month than February & $19.3 \%$ & $11.8 \%$ & $18.1 \%$ & $16.3 \%$ \\
Exactly the same amount of money in the past month as in February & $28.1 \%$ & $45.7 \%$ & $37.8 \%$ & $37.4 \%$ \\
Probably less money in the past month than February & $22.4 \%$ & $14.7 \%$ & $14.9 \%$ & $17.2 \%$ \\
Definitely less money in the past month than February & $13.2 \%$ & $17.7 \%$ & $10.1 \%$ & $13.8 \%$ \\
Total & $100.0 \%$ & $100.0 \%$ & $100.0 \%$ & $100.0 \%$ \\
\hline
\end{tabular}

Table 8 If you compare your behaviour during the last four weeks with that of the four weeks of February of this year, do you think that during the last four weeks you have purchased or consumed cultural products (e.g. books or e-books, online visit to a museum, theatre, opera or concert) [Corrected by dropout effects]

\begin{tabular}{lrrrr}
\hline Behavioural: Cultural consumption & \multicolumn{1}{l}{ SP } & \multicolumn{1}{l}{ UK } & \multicolumn{1}{l}{ IT } & Overall \\
\hline Definitely more in the past month than February & $9.4 \%$ & $5.5 \%$ & $9.8 \%$ & $8.1 \%$ \\
Probably more in the past month than February & $16.1 \%$ & $11.0 \%$ & $15.0 \%$ & $14.0 \%$ \\
Exactly the same number in the past month as in February & $27.7 \%$ & $44.8 \%$ & $36.3 \%$ & $36.5 \%$ \\
Probably less in the past month than February & $13.8 \%$ & $11.9 \%$ & $11.1 \%$ & $12.3 \%$ \\
Definitely less in the past month than February & $33.0 \%$ & $26.8 \%$ & $27.8 \%$ & $29.1 \%$ \\
Total & $100.0 \%$ & $100.0 \%$ & $100.0 \%$ & $100.0 \%$ \\
\hline
\end{tabular}

residence in the three countries (data from Eurostat), and the other with the proportions from the first wave. The original sample has similar proportions along these three dimensions (see SOM Table S13). 
Table 9 If you compare your behaviour during the last four weeks with that of the four weeks of February of this year, do you think that during the last four weeks you have stayed in contact with people relevant for your carrier, status or your future possibility to get a job [Corrected by dropout effects]

\begin{tabular}{lrrrr}
\hline Behavioural: Social capital & SP & UK & IT & Overall \\
\hline Definitely more times in the past month than February & $3.8 \%$ & $4.8 \%$ & $4.2 \%$ & $4.3 \%$ \\
Probably more times in the past month than February & $7.4 \%$ & $7.3 \%$ & $7.0 \%$ & $7.2 \%$ \\
Exactly the same number of times in the past month as in February & $31.1 \%$ & $53.2 \%$ & $38.4 \%$ & $41.2 \%$ \\
Probably less times in the past month than February & $16.2 \%$ & $14.0 \%$ & $16.9 \%$ & $15.7 \%$ \\
Definitely less times in the past month than February & $41.5 \%$ & $20.6 \%$ & $33.7 \%$ & $31.6 \%$ \\
Total & $100.0 \%$ & $100.0 \%$ & $100.0 \%$ & $100.0 \%$ \\
\hline
\end{tabular}

Table 10 If you compare your behavior during the last four weeks with that of the four weeks of February of this year, do you think that during the last four weeks you have adhered to an unhealthy lifestyle (e.g. consumption of unhealthy food, tobacco, alcohol, drugs, unprotected sex, lack of adherence to medication) [Corrected by dropout effects]

\begin{tabular}{lllll}
\hline Behavioral: Unhealthy & SP & UK & IT & Overall \\
\hline Definitely more times in the past month than February & $7 \%$ & $7 \%$ & $7 \%$ & $7 \%$ \\
Probably more times in the past month than February & $16 \%$ & $16 \%$ & $16 \%$ & $16 \%$ \\
Exactly the same number of times in the past month as in February & $41 \%$ & $53 \%$ & $50 \%$ & $48 \%$ \\
Probably less times in the past month than February & $14 \%$ & $10 \%$ & $11 \%$ & $12 \%$ \\
Definitely less times in the past month than February & $22 \%$ & $14 \%$ & $15 \%$ & $17 \%$ \\
Total & $100.0 \%$ & $100.0 \%$ & $100.0 \%$ & $100.0 \%$ \\
\hline
\end{tabular}

The estimated random forest model for selection bias is reported in the SOM (Figure S 1 and Tables S1-S2) as well: we report the OOB-error convergence, which stabilizes after 100 iterations at somewhere below 0.30 , the matrix of variable importance for each variable used when building the classifier, and the fit of the model (Spearman rank-order correlation coefficient $=0.7956, p=0.000$ ) between the dropout and the estimated dropout probability. The results are highly correlated when we compare total sample and out-ofsample prediction with $10 \%, 15 \%, 33 \%, 50 \%$ and $70 \%$ of the sample for learning. From the diagnostic tests, we conclude in favour of the robustness of the exercise.

The first question asked is about the general economic outlook for 2021 (Table 1). Overall, only $15.2 \%$ did not expect a change with respect to the current situation, $55.9 \%$ expected it to be worse, and $19.2 \%$ better. Slightly less than $10 \%$ did not provide an answer. There are differences across countries: pessimism was the highest in Spain, where $62.6 \%$ expected a worse year, while the rate was $58.9 \%$ in UK and $45.9 \%$ in Italy.

When asked about the expectation for the personal job situation (Table 2), citizens' belief was less pessimistic, with a $43 \%$ overall that saw a stable prospect with respect to the ongoing year (already a year of crisis, though). On average, $27.2 \%$ saw a worse job situation in 2021, the highest was in Spain again, with a share of $34.8 \%$, followed by Italy with $26.8 \%$ and the UK with $20.4 \%$.

In terms of recovery and going back to normal (Table 3), 39.2\% overall expected the recovery to take from six months to one year, whereas $37.7 \%$ more than one year. In this case, the grimmest prospect was offered by British beliefs, where $81.6 \%$ expected the 
recovery to last at least six months. This share decreased to $76.1 \%$ in the case of Spain, and $72.3 \%$ for Italy.

In the following three questions, we asked about fears. In particular, we asked participants to evaluate the likelihood of three negative scenarios: a new outbreak of the pandemic, an economic depression, and the permanent restriction on rights and freedom. Results are presented in Tables 4, 5 and 6 below. The first scenario was considered somewhat likely or very likely by $83.7 \%$ overall, increasing up to $90.9 \%$ in Spain, whereas it was $84.4 \%$ in the UK and $76.1 \%$ in Italy. Economic depression was estimated as somewhat likely or very likely by $91 \%$ of the population in the three countries: $92.4 \%$ in Spain, $90.3 \%$ in the UK, and $90.5 \%$ in Italy. A permanent restriction on rights and freedom was seen less likely but still a credible scenario for the majority of the population: $56.2 \%$ saw it as somewhat likely or very likely, with $65.3 \%, 49.4 \%$, and $54.3 \%$ respectively for Spain, the UK, and Italy.

The next set of questions is related with behavioural change. We asked participants to compare the behaviour during the last month with respect to the four weeks of February. This was necessary to provide a point in time without pandemic that was close enough to make them estimate reasonably the difference. Participants are asked to evaluate on a fivepoints Likert scale from definitely more to definitely less. The behaviours considered were four: withdrawal from savings, consumption of cultural products, staying in contact with people relevant for your career, status or your future possibility to get a job, and adoption of risky health behaviour. We report the results in Tables 7, 8, 9 and 10 below.

Overall, $37.4 \%$ used their saving in exactly the same proportion, while $31.6 \%$ used probably or definitely more. In Spain, $28.1 \%$ withdrew in the same proportion and $36.3 \%$ withdrew more. In the UK, $45.7 \%$ withdrew in the same proportion, and $21.9 \%$ did it more. In Italy, $37.8 \%$ and $37.3 \%$ did it respectively the same and more. In terms of consumption of cultural products, $36.5 \%$ bought it in the same proportions, while $22.1 \%$ did it more. The proportions are $27.7 \%$ and $25.5 \%$ for Spain, $44.8 \%$ and $16.5 \%$ for the UK, and $36.3 \%$ and $24.8 \%$ for Italy. In terms of maintenance of social capital, $41.2 \%$ invested the same amount of time, while $47.3 \%$ spent less. These proportions were $31.1 \%$ and $57.7 \%$ for Spain, $53.2 \%$ and $34.6 \%$ for the UK, and $38.4 \%$ and $50.6 \%$ for Italy. Finally, $48 \%$ adopted risky behaviour the same number of times, while $23 \%$ did it more. The proportions were $41 \%$ and $36 \%$ for Spain, $53 \%$ and $24 \%$ for the UK, and $50 \%$ and $26 \%$ for Italy.

\subsection{Results of the Estimation with Matching}

We now move to describe the results of the matching estimation. We recall that we used two estimators: propensity score matching (PSM) and Mahalanobis distance (MDM). PSM compares the participants who received more than the median of shocks with respect to those that did not but are closest in terms of predicted likelihood to be treated, according to a logistic estimation and using the following variables as predictors: [Sociodemographic module] age, gender, married, unemployed, homeownership, number of people in home, number of children in school, education level, household income, urban residency; [Preferences module] negative and positive reciprocity, altruism, trust, time preferences, risk preferences and cognitive function; [Health condition module] health condition, long-standing illness, long-term medical treatment, number of visits to doctor past year, comorbidity; [Vulnerability module] need to earn an income, need to care for others outside your home, do not want to miss certain social events/gatherings, urge to practice sports, and need to leave the house for some time (results in SOM Table S14). MDM follows a similar logic, 
but in this case the closeness is assessed in terms of a distance applied to all predictors. We also computed two estimators that correct for the bias induced by the fact that the closeness in terms of this set of variables is not perfect (i.e. we will not find two units with exactly the same characteristics).

For PSM, we assessed both the common support and the balancing of covariates between the group of higher exposure to shock (treated) and lower exposure to shocks (control). In SOM Figure S2, we report the common support used in the matching, in total 3188 observations are on support and 3 observations are off support. Table S15 shows the mean comparison for the covariates after and before the matching and the same comparison for the synthetic measure of the propensity score. These diagnostics show that matching reduces the bias between groups by $100 \%$ (i.e. we are effectively comparing units with the same likelihood of getting the severe shocks). Furthermore, there is a considerable bias reduction in terms of the covariates after the matching, with respect to the ex-ante comparison between severely and non-severely hit participants: in fact, the average bias in the covariates went from 24.7 to 3.1 after the matching. The balance between treated and control groups is confirmed when we test the overall measures of covariates imbalance after matching (Chi2 $=32.89, p=0.240)$. In fact, the absolute standardized difference of the means of the linear index of the propensity score in the treated and (matched) non-treated group, also called Rubins' B, is 21.2 after matching and the ratio of treated to (matched) non-treated variances of the propensity score index, also called Rubins' $R$, is 1.02 after matching. In order to consider a matching as sufficiently balanced, it is recommended to have a Rubins' B less than 25 and a Rubins' R between 0.5 and 2 (Rubin, 2001,).

To understand the results of the estimation from a quantitative point of view, we rescaled the outcome variables in the following way. In the first block (beliefs or expectations), for the first two variables related to economic and personal job outlook, we assign a value of 1 when the answer is "better", 0 when the answer is "the same", and -1 when the answer is "worse". Notice that we exclude those answering "I don't know", to have a meaningful ordinal ranking. The third variable (belief of the length of the recovery) do not need a transformation because it already has an ordinal order, the larger the value of the variable, the longer it is believed that the recovery will take. In the second block, for the three variables related to fear of a new outbreak of the disease, economic depression and restrictions of rights and freedom, we create a dummy variable with the value of 1 when the answer is very likely or somewhat likely, and 0 when the answer is very unlikely or somewhat unlikely. For the third block of variables: savings, cultural consumption, social capital, and unhealthy lifestyle, we assign a value of 2 to the answer definitely more, 1 to probably more, 0 to the same, -1 to probably less, and -2 to definitely less.

In Fig. 1, on the y-axis, we represent the three blocks of outcome variables, while on the x-axis, we indicate the size of the Average Treatment Effect on the Treated (ATT). The ATT is interpreted as the variation in outcome variable that occurred, ceteris paribus, because of the increase in exposure to shock above the median. Each small circle is the point estimate, while the segment represents the $95 \%$ confidence interval. In SOM, Table S16, we report the point estimate and the standard error for each outcome variable across methods.

As can be seen in Fig. 1, the ATT differs among the outcome variables but in general, is robust within outcome, across the four matching methods. Let us start from the beliefs block. We found no evidence of an effect by the increase in exposure to shock, neither on the economic outlook nor on the belief of time of recovery. In fact, the null hypothesis of absence of effect is not rejected neither in PSM (for economic outlook: $t=-1.05$, $p=0.292$; with bias correction: $\mathrm{t}=-1.04, \mathrm{p}=0.299$, and for time of recovery: $\mathrm{t}=-0.82$, 
$p=0.410$; with bias correction: $\mathrm{t}=-0.73, \mathrm{p}=0.468$ ) nor in MDM (for economic outlook: $\mathrm{t}=-0.38, p=0.704$; with bias correction: $\mathrm{t}=-1.21, p=0.226$, and for time of recovery: $\mathrm{t}=-0.36, p=0.718$; with bias correction: $\mathrm{t}=1.54, p=0.123$ ). However, personal job prospect was strongly and negatively affected by the increase in exposure to shock above the median, specifically, the point estimation of the ATT among methods varies between -0.18 and -0.16 . The result was confirmed by the rejection of the null hypothesis of absence of effect in both PSM $(\mathrm{t}=-3.77, p=0.000$; with bias correction: $\mathrm{t}=-4.14, p=0.000)$ and $\operatorname{MDM}(\mathrm{t}=-4.36, p=0.000$; with bias correction: $\mathrm{t}=-3.61, p=0.000)$.

For the second block, we found mixed evidence of shocks on fear of a new outbreak of the disease, an economic depression, and restrictions of rights and freedom. Particularly, we fail to reject the null hypothesis of absence of effect with PSM (new outbreak disease: $\mathrm{t}=-0.79, p=0.430$; with bias correction: $\mathrm{t}=-0.94, p=0.347$, economic depression: $\mathrm{t}=-1.54, \mathrm{p}=0.124$; with bias correction: $\mathrm{t}=-1.54, p=0.124$, and restrictions of rights: $\mathrm{t}=-0.30, p=0.765$; with bias correction: $\mathrm{t}=-0.32, p=0.745)$. Nevertheless, according to the MDM estimator, the null hypothesis of absence of effect is usually rejected (in two out of three cases without correction and in all cases with correction) at $10 \%$ of significance (new outbreak disease: $\mathrm{t}=-2.36, p=0.018$; with bias correction: $\mathrm{t}=-1.97, p=0.049$, an economic depression: $\mathrm{t}=-3.06, p=0.002$; with bias correction: $\mathrm{t}=-2.25, p=0.024$, and restrictions of rights: $\mathrm{t}=-0.05, p=0.958$; with bias correction: $\mathrm{t}=-1.90, p=0.057$ ). To conclude, based on MDM results, being severely exposed to shock had a negative impact on the fear of a new outbreak, of an economic depression, or of a restriction of rights and freedom.

Finally, in the third block, we found no evidence of shocks on cultural consumption or on unhealthy lifestyle. In fact, the null hypothesis of absence of effect is not rejected with PSM (for cultural consumption: $\mathrm{t}=0.05, p=0.961$; with bias correction: $\mathrm{t}=0.21, p=0.835$, and for unhealthy lifestyle: $\mathrm{t}=-0.08, p=0.940$; with bias correction: $\mathrm{t}=0.05, \mathrm{p}=0.958$ ) or with MDM (for cultural consumption: $\mathrm{t}=1.49, p=0.135$; with bias correction: $\mathrm{t}=0.91$, $p=0.365$, and for unhealthy lifestyle: $\mathrm{t}=-0.25, p=0.800$; with bias correction: $\mathrm{t}=-0.70$, $p=0.486$ ). On the other hand, the use of savings was strongly and positively affected by an increase in the exposure to shock, whereas the maintenance of relational capital was negative affected. In particular, the ATT size on the use of savings is between 0.29 and 0.43 depending on the estimator (for PSM: $\mathrm{t}=5.96, p=0.000$; with bias correction: $\mathrm{t}=6.67$, $p=0.000$, and for MDM: $\mathrm{t}=8.02, p=0.000$; with bias correction: $\mathrm{t}=4.47, p=0.000$ ) and for social capital the ATT size varies between -0.11 and -0.14 (for PSM: $t=-2.43$, $p=0.015$; with bias correction: $\mathrm{t}=-2.11, p=0.035$, and for MDM: $\mathrm{t}=-2.40, p=0.016$; with bias correction: $\mathrm{t}=-1.96, p=0.051$ ).

Notice that in SOM, Figure S3 we report the results using the 60th percentile of negative shocks as threshold for treatment status. Results are almost identical. ${ }^{7}$

\footnotetext{
7 By summing all shocks, we are technically giving equal weights in the index. To control for sensitivity to this methodological choice, in SOM Figure S4, we report the analysis when we build the index via principal component analysis: we extract the normalized first component, and we split participants considering treated those above the median. The results are very robust.
} 


\section{Discussion and Conclusions}

In this article, we have shown the beliefs, fears, and behavioural changes of citizens in three countries (Spain, the United Kingdom and Italy), on the verge of the post Covid-19 first wave. We have discussed how the crisis always forces citizens to reassess their beliefs, their fears and their behaviour. We postulate that the climate of uncertainty and the exposure to shocks that occurred during the crisis were likely to shape those outcome variables. This contribution fills a gap in the current literature on the effects of Covid-19 and related lockdown mitigation strategy where evidence is largely missing on how the gradient of exposure to negative shocks has shaped expectations and emotions about the future, and behavioural change. We did so, by presenting a novel database from a longitudinal study conducted in three waves in Spain, the United Kingdom and Italy between April 24 and May 20 (Bogliacino et al. 2020). We focussed on the data from the third wave on expectations (general, labour market situation, recovery), fear (scenario of new outbreak, economic depression, restriction to individual rights and freedom), and behavioural change across the following dimensions: savings, cultural consumption, social capital, unhealthy lifestyle. We used, however, also the data from wave 1 and wave 2 to control for the effects of, respectively, socio-economic background and health status (from wave I), and the indirect effect via cognitive performances and preferences (from wave II).

At descriptive level, the findings support our initial hypotheses, showing that most of the respondents in the three countries report negative expectations about the future and appear entrenched by possibly unjustified fears about extremely negative scenarios. The descriptive results are consistent with the hypothesis that, given the objective and subjectively perceived radical uncertainty and the framing adopted by governments and the media, even those individuals who were not severely impacted by the pandemic and/or lockdown have updated their expectations about the future and are fearful about what awaits in the coming months. Two findings from those presented earlier suffice here to support this statement: $56 \%$ of the sample expected 2021 to be worse than 2020; an economic depression was considered somewhat likely or very likely by $91 \%$ of sample. Descriptive data are also quite unequivocal on the fact that this has produced sizeable behavioural changes for what concerns savings and social capital. Almost one third of the sample was forced to use their savings during lockdown more than in last month before the outbreak of Covid-19. This evidence suggests a tangible behavioural change and a source of worry that feeds back into the creation of negative expectations and fears. As much as $47.3 \%$ of the sample has lost contact with people relevant for their career, status or the future possibility to get a job during the lockdown as compared to before the outbreak of the pandemic. Behavioural changes are less pronounced for what concerns risky health behaviour and more polarized for the case of cultural consumption. Only $23 \%$ of the sample indicated that they adopted unhealthier lifestyle during the lockdown compared to before. On the other hand, for cultural consumption $22.1 \%$ have increased it, 36.5 maintained the same pattern, and $41.4 \%$ consumed less.

We presented a DAG positing that negative shocks have a direct effect on our outcome variables, an indirect effect via cognitive ability and preferences, and are potentially confounded by socio-economic background, and health status. Controlling for the latter three causal paths via adoption of a selection on observables research design, we have been able to conclude that the gradient of exposure to negative events (above the median) has statistically significant effects on six out of 10 outcomes. First, being severely exposed to shocks determined stronger negative expectations about one's future jobs prospects. Second, the 
severity of exposure decreased the fears of an economic depression, of a new outbreak of the pandemic, and of permanent limitations to our freedom and rights, although the result was not robust to the choice of the estimator. Third, individuals who were more severely exposed to shocks used their saving more than before the pandemic outbreak in ways that are more marked than had they not experienced. Fifth, the same applied to social capital in that strong negative shocks led individuals to disregard instrumental social relations more than in presence of milder exposure to shocks.

With respect to the latter findings, it is important to remark, in particular, the first and the last results for, if consolidated, could lead to a negatively self-propelling loop. It is known that income and employment shocks exert negative effects on social capital reducing the social networks that help the unemployed to find new opportunities (Machin \& Manning, 1998). Decades of research demonstrate that social connections are vital to wellbeing and coping with difficult situations (Sibley et al., 2020) and that those without social connections and with pre-existing vulnerabilities may be more at risk. As high exposure to shocks is making individuals, at the same time, more pessimistic on their jobs' prospect and using less their social capital, there is a short-term negative interaction effect that may become a long-term effect, especially if expectations and fears are reinforced. Furthermore, the sociological literature and the literature on the psychology of class already tell us that more vulnerable groups are less used to take advantage of social capital and tend to interpret constraints and the structure of opportunities in self-limiting way. This already entrenched patterns could be multiplied by the negative shocks produced by Covid-19 and related lockdown mitigation strategies, so that the impact of the latter would become even more unequal than it is currently being shown to be. The emerging studies cited in the introduction about the inequality effect of lockdown, in fact, focus only on the tangible dimensions. Our findings suggest that there is a less tangible dimension related to habitus, beliefs, and emotions that could further exacerbate the inequalities generated by the pandemic and lockdown.

One of the strengths of the current study is that we have conducted data collection in three separate countries that have been more severely hit by the Covid-19 than other European countries. Second, the richness of the data made it possible to provide a characterization of the outcome variables that is representative of the population of interest (external validity), and to estimate a plausible counterfactual of exposure to shock to identify the causal impact (internal validity). Third, as the literature on Covid-19 is expanding rapidly, only limited studies have focused on the psychological, social, and economic consequences of the current economic halt. Nonetheless, the current study also has some limitations. First, although our surveys have been conducted for several weeks, following the panel for a longer period would have provided us with a better understanding of the long-term effects of the pandemic and the lock-down situation on people's health and well-being, and of course ideally, one would have included a baseline pre-lockdown. Second, this study focused on three countries that have been hit hardest by the pandemic, whereby Spain and Italy had very strict lockdown regulations. If we would have included also countries that have experienced less health consequences of the Covid-19, such as Eastern European countries, or countries that implemented less strict regulations, such as the Netherlands and Germany, the comparisons between countries could have been richer. Third, regional variations are also very important to understand the first wave of the Covid-19, as it was clearly the case for Italy, but exploring them was beyond the scope of this paper.

Our findings have clear policy implications. From the first set of results, we infer the need for policies that are able to restore hope and reduce radical uncertainty. Government ought to present the citizenry with contingent mid-term plan, not only in terms of public 
budget resources earmarked to the purpose. Particularly, they should mitigate fears that very pessimistic scenarios will occur. The second set of implications from the results concerns the consequences of shocks. Government should recognize that the degree of exposure has been heterogenous and should design new instruments of social policy and social assistance that provide coverage even to those households which are normally outside the range of social insurance schemes, softening the deaccumulation that took place from private assets and savings. Moreover, they might introduce active labour market policies to counteract the neglect of important networking activities during the lockdowns. Finally, they should mitigate negative job prospect expectations, as this may lead to an exit of the labour force with detrimental consequences in the long term.

Supplementary Information The online version contains supplementary material available at https://doi. org/10.1007/s11205-021-02697-5.

Acknowledgement We thank Noe Andreu for help with the programming and the data collection and Douglas Rodríguez who helped as RA. We appreciate suggestions by Laura Jimenez and Ricardo Macías for the design of the behavioural change questions in the questionnaire. The editor and two anonymous referees have been very helpful. The standard disclaimer applies. The authors declare no conflict of interest.

Funding Funding has been provided by Open Evidence and BDI-Schlesinger Group.

\section{References}

Abramson, L. Y., Metalsky, G. I., \& Alloy, L. B. (1989). Hopelessness depression: A theory-based subtype of depression. Psychological Review, 96(2), 358-372. https://doi.org/10.1037/0033-295X.96.2.358

Adams-Prassl, A., Boneva, T., Golin, M., \& Rauh, C. (2020a). Inequality in the Impact of the Coronavirus Shock: New Survey Evidence for the UK. https://doi.org/https://doi.org/10.17863/CAM.52477

Adams-Prassl, A., Boneva, T., Golin, M., \& Rauh, C. (2020b). Inequality in the Impact of the Coronavirus Shock: Evidence from Real Time Surveys. IZA DP No. 13183. Available https://www.iza.org/publi cations/dp/13183/inequality-in-the-impact-of-the-coronavirus-shock-evidence-from-real-time-surveys

Andreoni, J., \& Miller, J. (2002). Giving according to GARP: An experimental test of the consistency of preferences for altruism. Econometrica, 70(2), 737-753. https://doi.org/10.1111/1468-0262.00302

Atkinson, A. B. (2015). Inequality. What can be done? Cambridge: Harvard University Press.

Baker, SR, Bloom, N, Davis, SJ, Terry, SJ (2020) COVID-Induced Economic Uncertainty. NBER, wp 26983

Banerjee, A. V., \& Duflo, E. (2007). The economic lives of the poor. Journal of economic perspectives, 21(1), 141-168.

Barrett, M. R., \& Chavas, J.-P. (Eds.). (2008). The economics of poverty traps. University of Chicago Press.

Barret, C. B., Carter, M. R., \& Chavas, J. P. (2019). The economics of poverty traps. In National Bureau of Economic Research Conference Report. The University of Chicago Press Books.

Bauer, M., Blattman, C., Chytilová, J., Henrich, J., Miguel, E., \& Mitts, T. (2016). Can war foster cooperation? Journal of Economic Perspectives, 30(3), 249-274. https://doi.org/10.1257/jep.30.3.249

Béland, D., Carstensen, M. B., \& Seabrooke, L. (2016). Ideas, political power and public policy. Journal of European Public Policy, 23(3), 315-317. https://doi.org/10.1080/13501763.2015.112216

Benford, R., \& Snow, D. (2000). Framing Processes and Social Movements: An Overview and Assessment. Annual Review of Sociology, 26, 611-639. Retrieved from http://www.jstor.org/stable/223459

Bennett, T., \& Silva, E. B. (2006). Introduction cultural capital and inequality: Policy issues and contexts. Cultural Trends, 15(2-3), 87-106. https://doi.org/10.1080/09548960600712777

Bergamini, E. (2020). How COVID-19 is laying bare inequality. Bruegel, Retrieved from https://www.brueg el.org/2020/03/how-covid-19-is-laying-bare-inequality/

Bibby, J., Everest, G., \& Abbs, I. (2020). Will COVID-19 be a watershed moment for health inequalities. The Health Foundation.

Bloom, N. (2009). The Impact of Uncertainty Shocks. Econometrica, 77(3), 623-685. https://doi.org/10. $3982 /$ ecta6248 
Bobbio, N. (1980). Stato, governo, societ. Per una teoria generale della politica. Democracy and dictatorship The nature and limits of state power. Turin: Einaudi.

Bogliacino, F., Codagnone, C., Montealegre, F., Folkvord, F., Gómez, C., Charris, R., \& Liva, G. (2021). Negative shocks predict change in cognitive function and preferences: Assessing the negative affect and stress hypothesis. Scientific Reports. https://doi.org/10.1038/s41598-021-83089-0

Bogliacino, F., Lupiáñez, F., Codagnone, C., Charris, R., Gómez, C., Folkvord, F., Montealegre, F., Veltri, G., Liva, G. (2020). Longitudinal study on behavioral, psychological, socio-economic effects induced by the exposure to CoViD-19, by government measures, and by communication strategies in three countries: Italy, Spain, and United Kingdom. SocArXiv. June 2. doi: 10.17605/OSF.IO/ TBYS6

Bogliacino, F., \& Montealegre, F. (2020). Do negative economic shocks affect cognitive function, adherence to social norms and loss aversion? Journal of the Economic Science Association, 6(1), 57-67

Bonanno, G. A., Brewin, C. R., Kaniasty, K., \& Greca, A. M. L. (2010). Weighing the costs of disaster: Consequences, risks, and resilience in individuals, families, and communities. Psychological Science in the Public Interest, 11(1), 1-49

Bourdieu, P. (1977). Outline of a theory of practice. Cambridge University Press.

Bourdieu, P. (1980). Le capital social: Notes provisoires. Actes de la Recherche En Sciences Sociales, 31(1), 2-3

Bourdieu, P. (1984). Distinction: A social critique of the judgement of taste. Harvard University Press.

Bourdieu, P. (1986). The forms of capital. In J. Richardson (Ed.), Handbook of theory and research for the sociology of education. (pp. 241-258). Greenwood.

Brunori, P., Maitino, M., Ravagli, L., \& Sclicone, N. (2020). Distant and Unequal. Lockdown and Inequalities in Italy. Unicaldine. Available at http://www.unicaldine.it/research/BMRS_2020.pdf

Carstensen, M., \& Schmidt, V. (2016). Power through, over and in ideas: Conceptualizing ideational power in discursive institutionalism. Journal of European Public Policy, 23(3), 318-337

Cassar, A., Healy, A., \& von Kessler, C. (2017). Trust, risk, and time preferences after a natural disaster: Experimental evidence from Thailand. World Development, 94, 90-105. https://doi.org/10.1016/j. worlddev.2016.12.042

Cavatorta, E., Zizzo, D. J., \&... Daoud, Y. (2020). Does exposure to violence affect reciprocity? Experimental evidence from the West Bank. Discussion Papers Series

Codagnone, C., Bogliacino, F., Gómez, C., Charris, R., Montealegre, F., Liva, G., \& Veltri, G. A. (2020). Assessing concerns for the economic consequence of the COVID-19 response and mental health problems associated with economic vulnerability and negative economic shock in Italy, Spain, and the United Kingdom. Plos one, 15(10), e0240876

Coleman, J. (1988). Social capital in the creation of human capital. The American Journal of Sociology, 94, S95

Coleman, J. (1990). Foundations of social theory. Harvard University Press.

Cunningham, AS (2018) The Causal Identification Mixtape v1.7 tufte-latex.googlecode.com

Decker, S., \& Schmitz, H. (2016). Health shocks and risk aversion. Journal of Health Economics, 50, 156-170. https://doi.org/10.1016/j.jhealeco.2016.09.006

Doney, P. M., Locke, E. A., Noorderhaven, N. G., Cannon, J. P., \& Mullen, M. R. (1999). Some reservations about social capital. Academy of Management Review, 24(1), 8-11.

Draghi, M. (2020, March 25). We face a war against coronavirus and must mobilise accordingly. Financial Times, Retrieved from https://www.ft.com/content/c6d2de3a-6ec5-11ea-89df-41bea055720b

Duan, L., \& Zhu, G. (2020). Psychological interventions for people affected by the COVID-19 epidemic. The Lancet Psychiatry, 7(4), 300-302

Eli, D., \& Rao, J. (2010). The good news-bad news effect: Asymmetric processing of objective information about yourself. American Economic Journal: Microeconomics.

Entman, R. (1991). Symposium framing US coverage of international news contrasts in narratives of the KAL and Iran Air incidents. Journal of Communication, 41(4), 6-27. https://doi.org/10.1111/j. 1460-2466.1991.tb02328.x

Entman, R. (1993). Framing: Toward clarification of a fractured paradigm. Journal of Communication, 43(4), 51-58

Eysenck, M. W. (2013). Anxiety: The cognitive perspective. New York: Psychology Press.

Falk, A., Becker, A., Chomen, T., Enke, B., Huffman, D., \& Sunde, U. (2018). Global evidence on economic preferences. The Quarterly Journal of Economics, 133(4), 1645-1692

Frederick, S. (2005). Cognitive reflection and decision making. Journal of Economic perspectives, $19(4), 25-42$

Garz, M. (2013). Unemployment expectations, excessive pessimism, and news coverage. Journal of Economic Psychology, 34, 156-168. https://doi.org/10.1016/j.joep.2012.09.007 
Gintis, H. (2007). A framework for the unification of the behavioral sciences. Behavioral and Brain Sciences, 30, 1-61

Goidel, K., Procopio, S., Terrell, D., \& Wu, H. D. (2010). Sources of economic news and economic expectations. American Politics Research, 38(4), 759-777. https://doi.org/10.1177/1532673x09355671

Grossman, Z., \& Owens, D. (2012). An unlucky feeling: Overconfidence and noisy feedback. Journal of Economic Behavior and Organization, 84, 510-524

Hale T., Webster S., Petherick A., Phillips T., and Kira B. (2020). Oxford COVID-19 Government Response Tracker, Blavatnik School of Government.

Hanspal, T., Weber, A., \& Wohlfart, J. (2020). Income and Wealth Shocks and Expectations during the COVID-19 Pandemic, CESifo Working Paper, No. 8244, Center for Economic Studies and Ifo Institute (CESifo), Munich. Avialable at https://www.econstor.eu/handle/10419/216640

Haushorfer, J., \& Fehr, E. (2014). On the psychology of poverty. Science, 344, 862-867. https://doi.org/10. 1126/science. 1232491

Ibáñez, A. M., \& Moya, A. (2010). Vulnerability of victims of civil conflicts: Empirical evidence for the displaced population in Colombia. WorldDevelopment, 38(4), 647-663. https://doi.org/10.1016/j.world dev.2009.11.015

Jann, B. (2017). kmatch: Stata module for multivariate-distance and propensity-score matching, including entropy balancing, inverse probability weighting, (coarsened) exact matching, and regression adjustment. Available from https://ideas.repec.org/c/boc/bocode/s458346.html

Jones, B. D., Thomas, H. F., \& Wolfe, M. (2014). Policy Bubbles. Policy Studies Journal, 42(1), 146-171. https://doi.org/10.1111/psj.12046

Jones, A. M., Rice, N., \& Zantomio, F. (2020). Acute health shocks and labour market outcomes: Evidence from the post crash era. Economics and Human Biology. https://doi.org/10.1016/j.ehb.2019.100811

Katz-Gerro, T. (2004). Cultural consumption research: review of methodology, theory, and consequence. International Review of Sociology, 14(1), 11-29. https://doi.org/10.1080/0390670042000186743

Kiess, J., \& Lahusen, C. (2018). An island of bliss-For everyone? Perceptions and experiences of the crisis across social classes in Germany. In M. Grasso \& M. Giugni (Eds.), Citizens and the crisis (pp. 189-214). Cham: Palgrave Macmillan.

Klandermans, B. (1997). The social psychology of protest. Blackwell.

Kuypers, J. (2010). Framing analysis as a rhetorical process. In P. D’Angelo \& J. Kuypers (Eds.), Doing news framing analysis. (pp. 286-311). Routledge.

Lenhart, O. (2019). The effects of health shocks on labor market outcomes: Evidence from UK panel data. The European Journal of Health Economics, 20, 83-98

Li, K. K. (2020) How Does the COVID-19 Outbreak Affect People's Expectation about the Macroeconomy?. Available at SSRN 3567937

MacFayden, A. J. (2006). Beliefs in behavioral and neoclassical economics. In M. Altman (Ed.), Handbook of contemporary behavioral economics, London, England and Armonk. New York: M E Sharpe.

Machin, S., \& Manning, A. (1998). The causes and consequences of long-term unemployment in Europe. CEPDP (400). Centre for Economic Performance, London School of Economics and Political Science, London, UK. ISBN 0753012332

Mani, A., Mullainathan, S., Shafir, E., \& Zhao, J. (2014). Poverty impedes cognitive function. Science, 341, 976-980

Manstead, A. S. R. (2018). The psychology of social class: How socioeconomic status impacts thought, feelings, and behaviour. British Journal of Social Psychology, 57, 267-291. https://doi.org/10.1111/ bjso. 12251

Maor, M. (2014). Policy persistence, risk estimation and policy underreaction. Policy Sciences, 47(4), $425-443$

Maor, M. (2016). Emotion-driven negative policy bubbles. Policy Sciences, 49(2), 191-210. https://doi.org/ 10.1007/s11077-015-9228-7

Mendola M, Bredenkamp C, Gragnolati M (2007). The Impoverishing Effect of Adverse Health Events: Evidence from the Western Balkans. Policy Research Working Paper 4444. Washington, DC: World Bank

Mobius, M.M., Niederle, M., Niehaus, P., \& Rosenblat, T.S. (2011). Managing Self-Confidence: Theory and Experimental Evidence. Working Paper 17014. National Bureau of Economic Research.

Moya, A., \& Carter, M. (2019). Violence and the formation of hopelessness: Evidence from internally displaced persons in Colombia. World Development, 113, 100-115

Mügge, D. (2016). Studying macroeconomic indicators as powerful ideas. Journal of European Public Policy, 23(3), 410-427

Nussbaum, M. (2004). Hiding from humanity: Disgust, shame, and the law. Princeton University Press. 
Öhman, A., (2007) Fear and anxiety Overlaps and dissociations In: Lewis M, Haviland-Jones JM, Barrett LF (eds) (Guilford, New York), pp 709-729

Pearle, J. (2009). Causality: Models, reasoning and inference. (2nd ed.). Cambridge University Press.

Perugini, C., \& Vladisavljevic, M. (2020). Social Stability Challenged: Pandemics, Inequality and Policy Responses, IZA Discussion Papers 13249, Institute of Labor Economics (IZA). Available at http://ftp. iza.org/dp13249.pdf

Pfefferbaum, B., \& North, C. S. (2020). Mental health and the Covid-19 pandemic. New England Journal of Medicine, 383, 510-512

Putnam, R. (1993). Marking democracy work: Civic traditions in Modern Italy. Princeton University Press.

Putnam, R. (2000). Bowling alone: The collapse and revival of american community. Simon and Schuster.

Rosenbaum, P. R., \& Rubin, D. B. (1983). The central role of the propensity score in observational studies for causal effects. Biometrika, 70(1), 41-55

Roth, R. H., Tam, S. Y., Ida, Y., Yang, J. X., \& Deutch, A. Y. (1988). Stress and the mesocorticolimbic dopamine systems. Annals of the New York Academy of Sciences, 537, 138-147

Rubin, D. B. (1977). Assignment to treatment group on the basis of a covariate. Journal of educational Statistics, 2(1), 1-26

Rubin, D. B. (2001). Using propensity scores to help design observational studies: application to the tobacco litigation. Health Services and Outcomes Research Methodology, 2(3), 169-188

Sartori, G. (1987). Theory of democracy revisited. New York: Chatam House.

Seabrooke, L., \& Wigan, D. (2016). Powering ideas through expertise: professionals in global tax battles. Journal of European Public Policy, 23(3), 357-374

Sibley, C. G., Greaves, L., Satherley, N., Wilson, M., Overall, N., Lee, C., ... Barlow, F. (2020). Effects of the COVID-19 Pandemic and Nationwide Lockdown on Trust, Attitudes towards Government, and Wellbeing. SocArXiv. April 2020. https://doi.org/https://doi.org/10.1037/amp0000662

Snow, D., \& Benford, R. (1988). Ideology, frame resonance, and participant mobilization. International Social Movement Research, 1, 197-217

Snow, D., Rochford, E., Worden, S., \& Benford, R. (1986). Frame alignment processes, micromobilization, and movement participation. American Sociological Review, 51(4), 464-481. https://doi.org/10.2307/ 2095581

StataCorp, 2017 Stata Statistical Software: Release 15 StataCorp LLC

Steijn, B., Berting, J., \& de Jong, M. J. (Eds.). (1998). Economic restructuring and the growing uncertainty of the middle class. Berlin: Springer.

Sunstein, C. R. (2018). The Cost-Benefit Revolution. The Cost-Benefit Revolution. https://doi.org/10.7551/ mitpress/11571.001.0001

Sympson, S. C. (2000). Rediscovering hope: Understanding and working with survivors of trauma. In C. R. Snyder (Ed.), Handbook of hope.Amsterdam: Elsevier.

Tabner, I. (2020). Five ways coronavirus lockdowns increase inequality. The Conversation, Retrieved from https://theconversation.com/five-ways-coronavirus-lockdowns-increase-inequality-135767

Textor, J., van der Zander, B., Gilthorpe, M. K., Liskiewicz, M., \&... Ellison, G. T. H. (2016). Robust causal inference using directed acyclic graphs: The R package "dagitty." International Journal of Epidemiology, 45(6), 1887-1894

The good news-bad news effect: Asymmetric processing of objective information about yourself. American Economic Journal: Microeconomics

Tversky, A., \& Kahneman, D. (1981). The framing of decisions and the psychology of choice. Science, 211(4481), 453. Retrieved from http://science.sciencemag.org/content/211/4481/453.abstract

Van Bavel, J. J., Baicker, K., Boggio, P. S., Capraro, V., Cichocka, A., Cikara, M., \& Drury, J. (2020). Using social and behavioural science to support COVID-19 pandemic response. Nature Human Behaviour, $25,1-12$

Varian, H. (1982). The nonparametric approach to demand analysis. Economica, 50(4), 945-976

Voors, M., Nillesen, J. E. E. M., Verwimp, P., Bulte, E., Lensink, R., \& Van Soest, D. (2012). Violent conflict and behavior: A field experiment in Burundi. American Economic Review, 102(2), 941-964

Wagstaff, A. (2007). The economic consequences of health shocks: evidence from Vietnam. Journal of health economics, 26(1), 82-100

Wilkinson, R., \& Pickett, K. (2009). The spirit level: Why more equal societies almost always do better. London: Allen Lane.

WHO (2020) WHO announces COVID-19 outbreak a pandemic, available at: https://bit.ly/3frWeLK Yehuda, R. (2002). Post-traumatic stress disorder. New England Journal of Medicine, 346, 108-114 Zou, R. Y. \& Schonlau, M. (2021). RFOREST: Stata module to implement Random Forest algorithm. 
Publisher's Note Springer Nature remains neutral with regard to jurisdictional claims in published maps and institutional affiliations.

\section{Authors and Affiliations}

\section{Cristiano Codagnone ${ }^{1,2,3}$. Francesco Bogliacino ${ }^{4,5}$ (D) Camilo Gómez ${ }^{4,5}$. Frans Folkvord ${ }^{2,6} \cdot$ Giovanni Liva $^{2} \cdot$ Rafael Charris $^{5,7} \cdot$ Felipe Montealegre $^{4,5}$. Francisco Lupiañez Villanueva ${ }^{2,3} \cdot$ Giuseppe A. Veltri $^{8}$}

1 Università Degli Studi Di Milano, Via Conservatorio 7, 20122 Milano, Italy

2 Open Evidence Research Group, Universitat Oberta de Catalunya, Avinguda del Tibidabo, 39-43 08035 Barcelona, Spain

3 Faculty of Information and Communication Science, Universitat Oberta de Catalunya, Avinguda del Tibidabo, 39-43 08035 Barcelona, Spain

4 Facultad de Ciencias Económicas, Universidad Nacional de Colombia, Carrera 30, No 45-03, Bogotá, Colombia

5 Centro de Investigaciones para el Desarrollo, Universidad Nacional de Colombia, Cl. 44 No 45-99, Bogotá, Colombia

6 Tillburg School of Humanities and Digital Sciences, Tilburg University, Warandelaan 2, 5037 AB Tilburg, The Netherlands

7 Economic Science Institute, Chapman University, One University Drive, Orange, CA 92866, USA

8 Department of Sociology and Social Research, Università Degli Studi Di Trento, via Verdi, 26 I-38122 Trento, Italy 